\title{
Behavior of expanded polystyrene as lightweight filler in retaining walls with intermediate slabs
}

\author{
J. M. Davila* \\ J. C. Fortes ${ }^{a}$
}

\section{A. Jaramillo-Morillab}

M. de la Torre ${ }^{a}$

\section{R. Pancho ${ }^{\mathrm{a}}$}

a University of Huelva. Andalucia Avenue s/n, 21007 - Huelva, Spain. E-mail: jmdavila@dimme.uhu.es, jcfortes@dimme.uhu.es, mltorre@dimme.uhu.es, pcrocio93@gmail.com

b University of Seville. Reina Mercedes Avenue 2, 41012, Seville, Spain. E-mail: jarami@us.es

* Corresponding author

http://dx.doi.org/10.1590/1679-78254776

\begin{abstract}
The present study explores a retaining wall with an intermediate slab. To reduce the lateral earth pressure on the wall, the substitution of part of the soil by blocks of expanded polystyrene (EPS) with high density is proposed, which could result in significant economic savings. Also, the possibility of building the wall elevation with smaller thickness (preexisting wall reinforcement) will be analyzed. To do this, the situation and optimum geometry of the EPS blocks will be studied in detail, besides a study of two scaled models, one without EPS and another with blocks with rectangular distribution. The obtained results allow us to affirm that the reduction in pressure is very significant if the blocks are arranged with the proper geometry and situation over the sliding plane but without eliminating the beneficial effect of the weight of the ground located over the slab.
\end{abstract}

\section{Keywords}

Stability, numerical analysis, expanded polystyrene, lightweight filler, scale models

\section{INTRODUCTION}

The intervention is aimed at conserving the archaeological remains of Utrera's Castle and solving the stability problems of the boundary slope of the castle courtyard in the area where the wall is located between the west and northwest towers and the northwest and north towers, respectively, as shown in Figure 1 (Lima, 2010). As can be seen in the figure, only the towers remain in the study area of the wall, while the wall has disappeared.

Taking into account the unevenness of the floor in the study area (around $7 \mathrm{~m}$ ), it is intended to take advantage of the low density of EPS (in this work, EPS will be used as blocks or rigid elements, which are available on the market in the form of resins called Geofoam that are used by injection), a characteristic that is applied in numerous examples in scientific texts like in Miao et al. (2013) and Davila et al. (2015), that analyze their properties and their possible applications, highlighting their use as a buffer element in seismic situations (Zarnani and Bathurst, 2009), their inclusion as an element of protection against expansive soils (Ikizler et al., 2007), and as proposed here, their use as a filler material or lightening element, mainly applied to cantilever walls (Ertugrul and Trandafir, 2013; Ertugrul and Trandafir, 2011; Horvath, 1997). 
The purpose of this work is to confirm the goodness of the solution for a retaining wall of considerable height with EPS lightened filling, while using an intermediate slab. In addition, an attempt will be made to determine the optimal geometry and position in such situations. Another alternative will try to evaluate the situation in which there is a preexisting wall from a previous intervention, also made of reinforced concrete and $3.65 \mathrm{~m}$ in height; in this case, the possibility of realizing the wall without the intermediate slab will be studied.

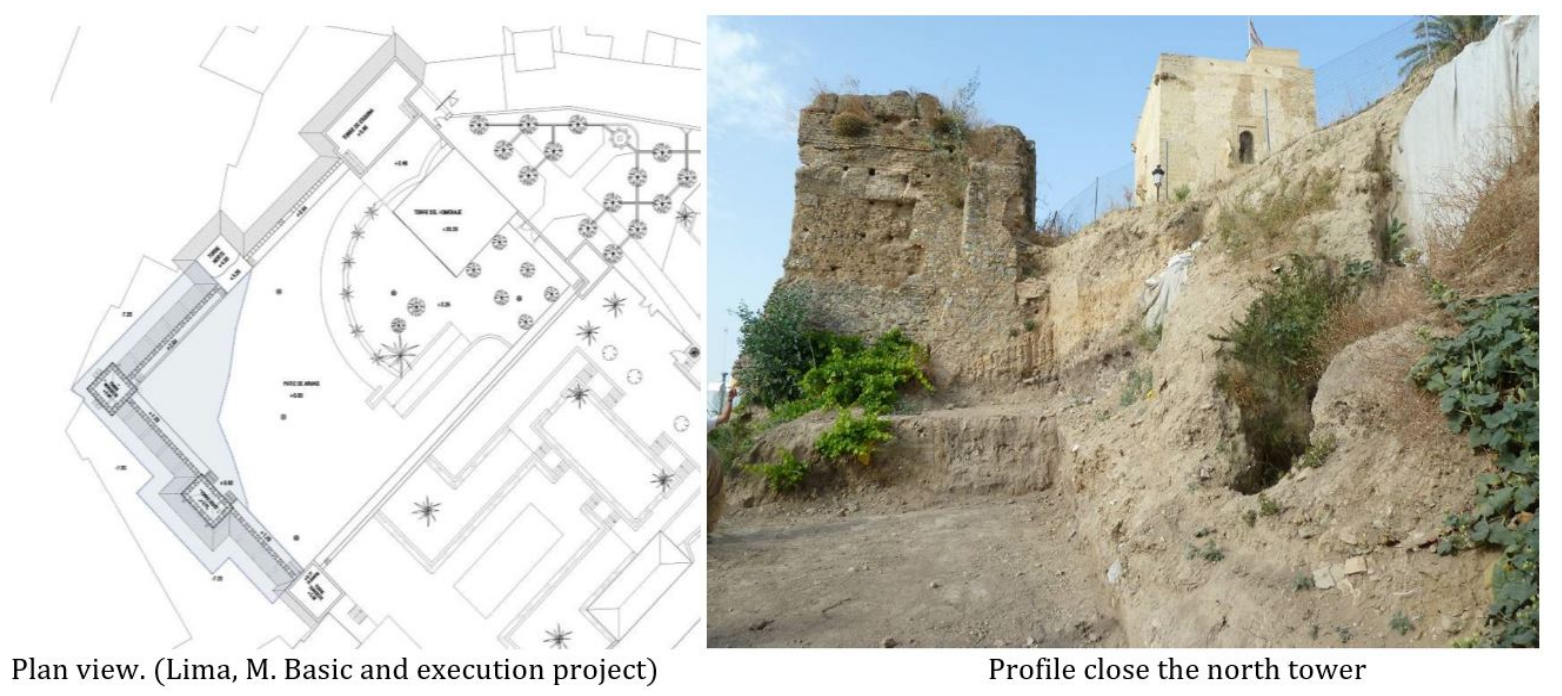

Figure 1: Intervention area.

This work is based on an earlier project, taken from Lima (2010), in which, on observing the first landslides, it was decided that the cantilever wall already mentioned with a height of $3.65 \mathrm{~m}$ should be executed. In this project, the execution of buttresses was contemplated but was ultimately not carried out. Later (July 2011), when it was observed that the problem had not been solved, and considering the deformations of the previous wall, the realization of walls with intermediate slabs was proposed in another project (Jaramillo, 2011). As a starting point, a geotechnical study (dated 2011) for the work on the new lookout tower of Utrera's Castle was consulted, which consisted of two rotary drillings and two dynamic soundings (Codexsa, 2011).

\section{PROPOSED SOLUTIONS}

Two different profiles have been considered, corresponding to the two sides of the wall studied. The first one, between the north and northwest towers, has a dip of $6.87 \mathrm{~m}$, while the one located between the west and northwest towers has a dip of $7.15 \mathrm{~m}$ and already has a wall $3.65 \mathrm{~m}$ high and $35 \mathrm{~cm}$ thick in its elevation (made of concrete HA-25 $-f_{c k}=25 \mathrm{MPa}$ ) that it will try to reinforce with other new wall connected by the inner face of it (Figures 2 and 3 ).

${ }^{1}$ The concrete is in all cases $\mathrm{HA}-25$, including the existing wall, as indicated in the project. 


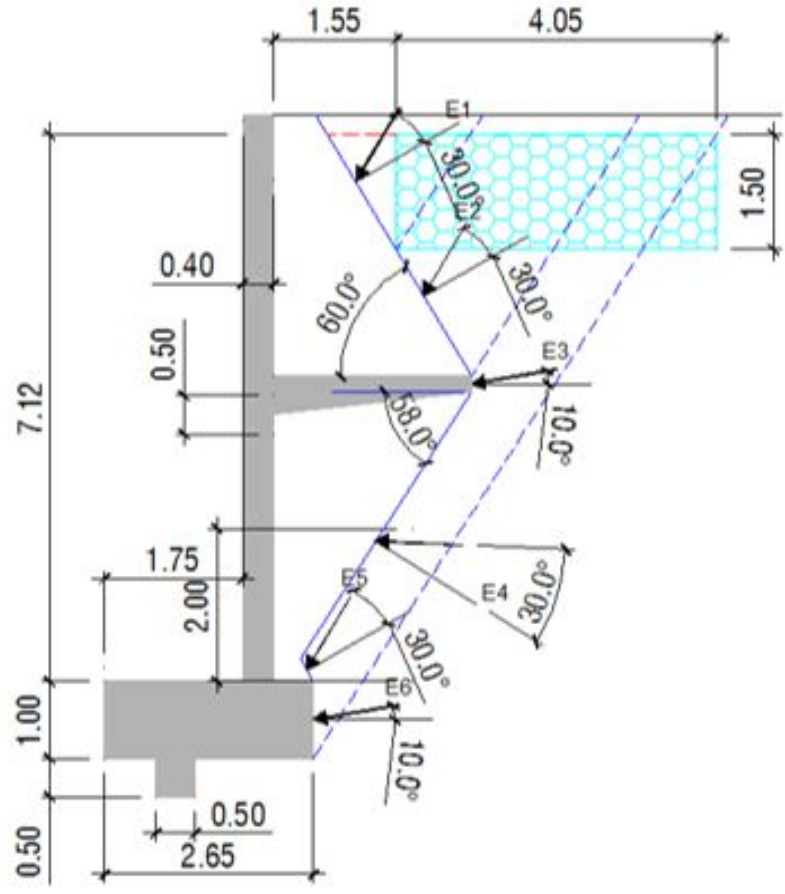

Solution 1.a

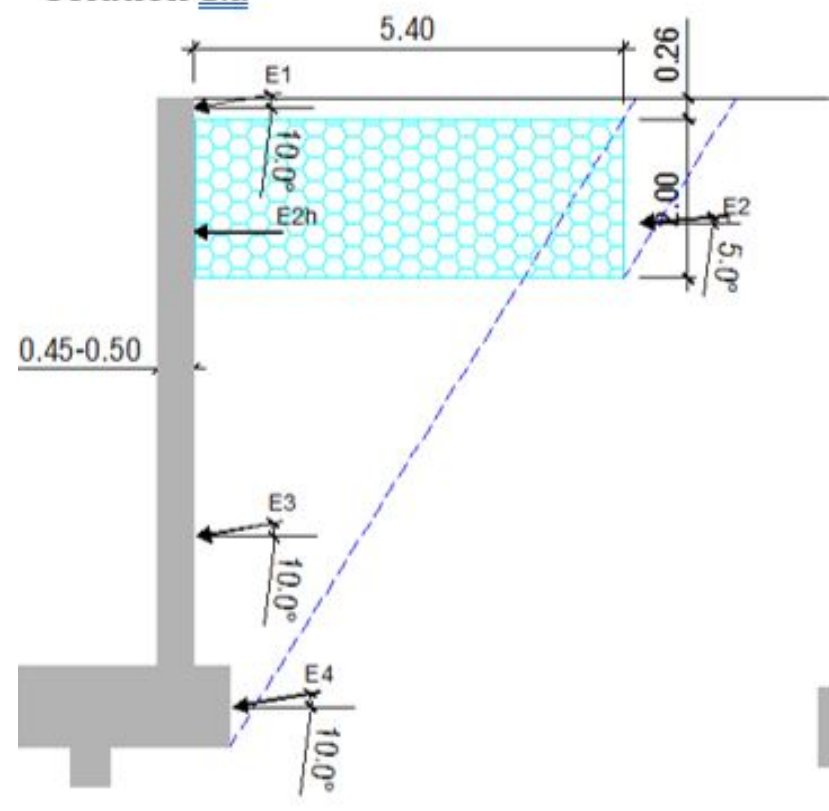

Solution 1.c

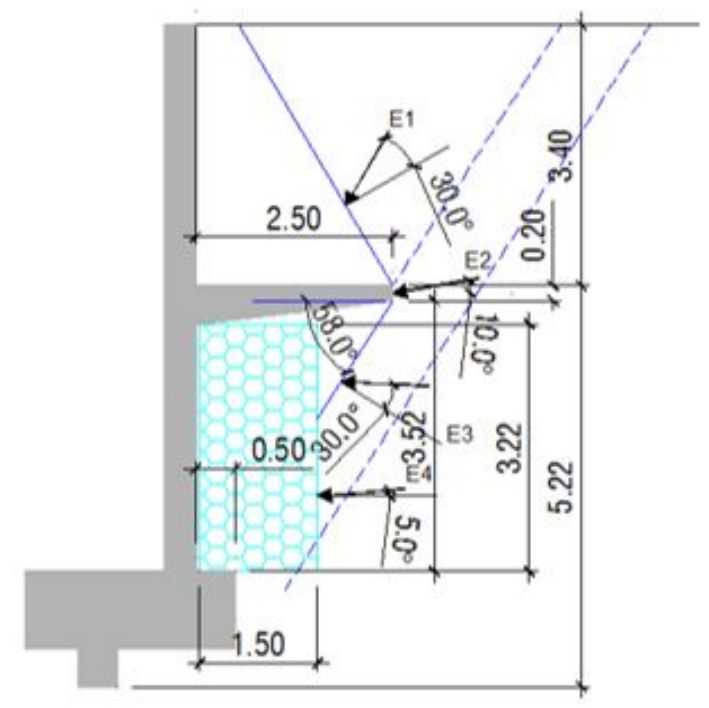

Solution 1.b

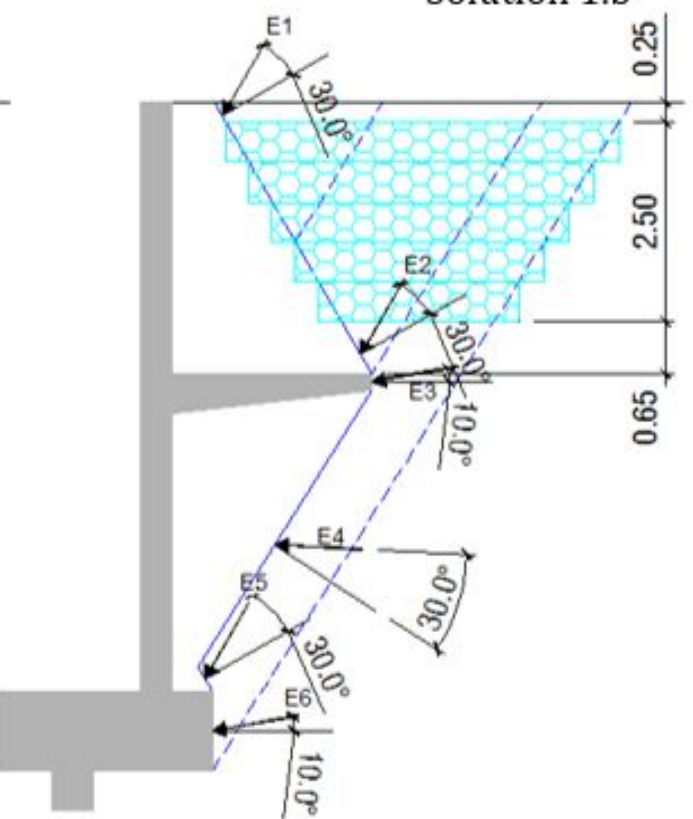

Solution 1.d

Figure 2: Solution 1.a. Over the slab, 1.b. Under the slab, 1.c. Wall without slab and 1.d. Stepped.

In response to these two profiles, different solutions have been given. For the first solution, several alternatives have been analyzed: placing the EPS blocks above the slab (1.a), placing them under the slab (1.b), and removing the intermediate slab (1.c) by enlarging the volume occupied by the polystyrene blocks; as a last alternative within the first option, a solution of stepped type is proposed, using blocks of about $50 \mathrm{~cm}$, so that the whole of the slip surface located in the upper part of the slab is occupied but without losing the positive effect of the land situated over it (1.d). These alternatives are presented in Figure 2. For the second solution, another set of alternatives has been analyzed: with the blocks of EPS above the slab in the area occupied by the slip surface, the option will be confirmed (as will be seen) as the most appropriate in the previous case (which is known as solution 1.a), and as the last possibility the intermediate slab could be removed, expanding the volume occupied by the EPS blocks, in the same way as in the solution 1. The alternative of placing the blocks below the slab was not studied here, while it is verified that solution 1.b is no longer available. 


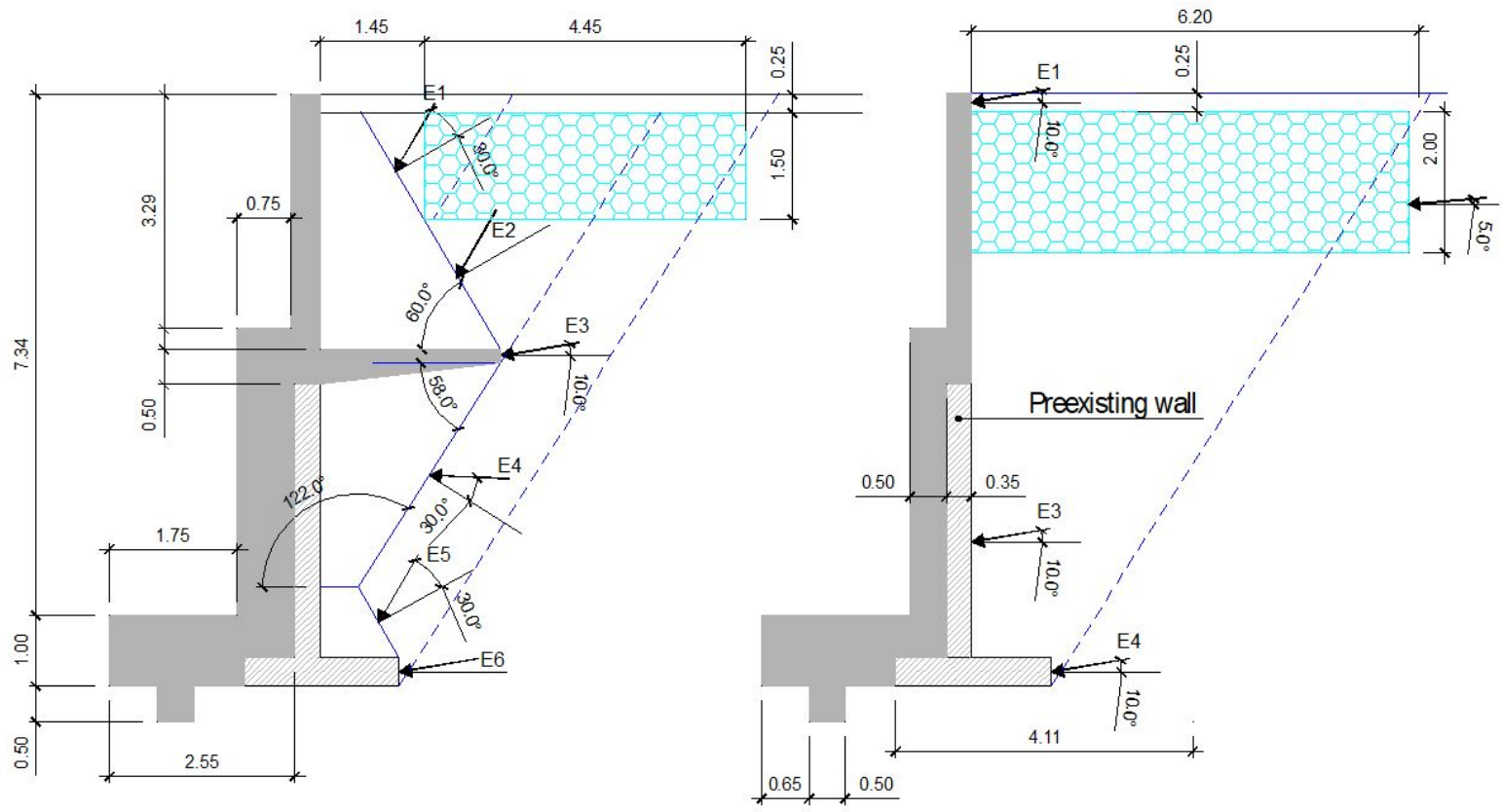

Solution 2.a

Solution 2.b

Figure 3: Solution 2.a. EPS over the slab, Solution 2.b. Wall without slab.

\section{MATERIALS AND METHODS}

A comparative calculation was performed by following the method proposed by Calavera (2001) on the one hand and using the finite element software Sap2000 (version 14) on the other hand, in order to study the structural behaviors of the different options. The program Plaxis 2D (version 8.2) was also used to analyze the options from a geotechnical point of view. For the analysis by the finite element program Sap2000, shell elements of four nodes and a thickness of $1 \mathrm{~m}$ were used, whereas to make the model using Plaxis 2D (2016, Plaxis 2D, Scientific Manual), triangular elements of six nodes with three degrees of freedom per node were used. Plane deformation conditions were considered in both cases. In the calculations done using Sap2000, the following calculation hypothesis were considered:

I. Soil pressure, both vertical and horizontal.

II. Weight of the soil above the slab (favorable with regard to sliding and but unfavorable with regard to bending of the slab).

III. Horizontal and vertical pressures produced by the uniform load of $5 \mathrm{kN} / \mathrm{m}^{2}$.

The following combinations of loads are taken into account:

$A=I ; B=I+I I ; C=I+I I I ; D=I+I I+I I I$

The initial data that have been used to make the different models have been obtained both from the manufacturers of the area close to the intervention and from different researchers (Lin et al., 2010; Negussey, 2008 and Valdbjørn, 2010) who have extensively studied the properties of EPS applied to geotechnics (Table 1).

To obtain the sliding surface, the Poncelet graphical method was used (Jiménez et al., 1981), starting from the angles $\phi(30 \circ)$ and $\phi+\delta(40 \%)$ and the slope angle $\beta(0 \circ)$, giving a value of J' of approximately 58․ Although the inclusion of the EPS blocks would alter the slope angle, on observing Figures 2 and 3, it can be verified that the sliding surface would cut the blocks in a small area, even smaller in solutions 1.a and 1.d, so it is understood that this effect does not have great relevance. In any case, this effect could be verified in the models made with Plaxis, where it caused a small increase of the sliding surface. 
Table 1: Material properties.

\begin{tabular}{cccccccc}
\hline & $\begin{array}{c}\text { Elasticity } \\
\text { Module } \\
(\mathbf{M P a})\end{array}$ & $\begin{array}{c}\text { Poisson } \\
\text { Coefficien } \\
\mathbf{v}\end{array}$ & $\begin{array}{c}\text { Specific } \\
\text { weight } \\
\left(\mathbf{k N} / \mathbf{m}^{3}\right)\end{array}$ & $\begin{array}{c}\text { Friction } \\
\text { angle } \\
\text { EPS-wall(o) }\end{array}$ & $\begin{array}{c}\text { Internal } \\
\text { friction } \\
\text { angle (o) }\end{array}$ & $\begin{array}{c}\text { Friction } \\
\text { angle of } \\
\text { soil-wall (o) }\end{array}$ & $\begin{array}{c}\text { Cohesion } \\
(\mathbf{k N} / \mathbf{m})\end{array}$ \\
\hline $\begin{array}{c}\text { Concrete } \\
\text { HA-25 }\end{array}$ & 25,000 & 0.2 & 24 & - & - & - & - \\
$\begin{array}{c}\text { Expanded } \\
\text { Polystyrene } \\
\text { Filler }\end{array}$ & 6 & 0.1 & 0.3 & 5 & - & - & - \\
$\begin{array}{c}\text { (2 m depth) } \\
\text { Muddy sands } \\
\text { (8 m depth) }\end{array}$ & 5 & 0.3 & 16 & - & 30 & 10 & 0 \\
\hline
\end{tabular}

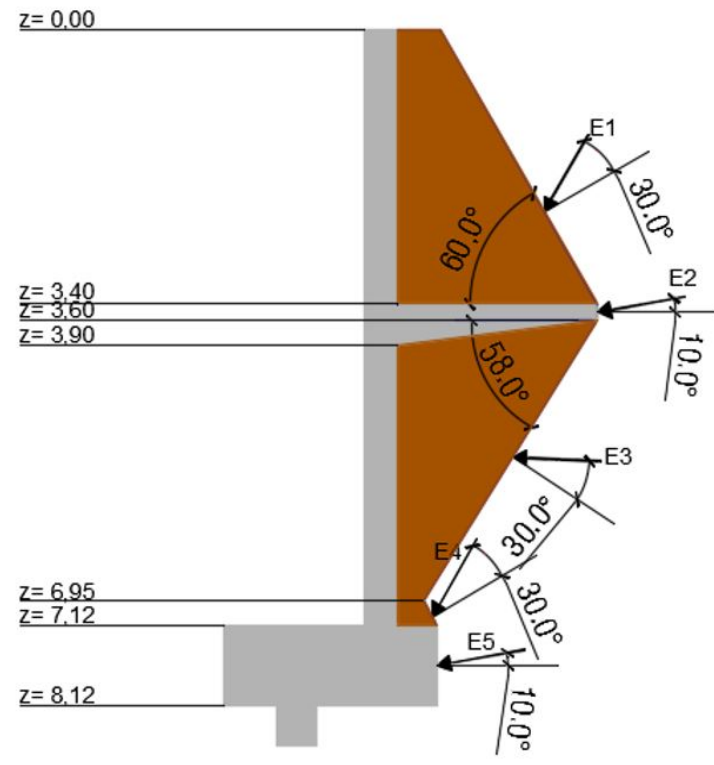

Figure 4.a:General thrust scheme for solution 1.

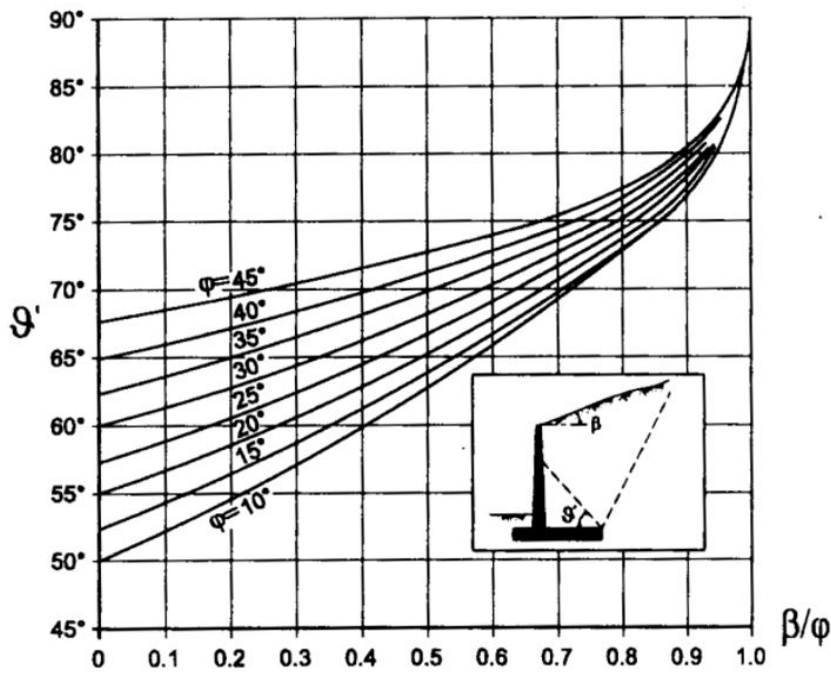

Figure 4.b:日’ angle (Verlag, 1966)

Figure 4: Graphical scheme.

In the case of the wall in solution 1, the general scheme of soil pressures would be the one shown in Figure 4, following what is indicated in Horvath (1997). For the pressures E1 and E4, the thrust acts at $30^{\circ}$ with the normal to the angle $\vartheta^{\prime}=60^{\circ}$ determined in the table of Figure 4 from angles $\beta$ and $\phi$. The thrusts E2 and E5 correspond to the law of Coulomb, with the pressures and thrust forming an angle $\delta$ (friction angle between ground and wall) with the normal to the outer face, while at thrust E3, the pressures form with the normal, the angle $\vartheta$ determined by the Poncelet procedure (Jiménez et al., 1981) (starting from approximately $58^{\circ}$ in our case), which results in $\phi=30^{\circ}$.

To calculate the coefficients of active earth pressure, Coulomb theory is followed (Coulomb, 1773), giving the following thrusts (Horvath, 1997)2:

Horizontal thrust $E_{h}=\gamma \cdot z \cdot \lambda_{h}+q \cdot \lambda_{h}$

Vertical thrust $E_{v}=\gamma \cdot z \cdot \lambda_{v}+q \cdot \lambda_{v}$

where $\gamma$ is the specific weight of each material,

$z$ is the depth and

$\lambda$ is the corresponding thrust coefficient.

\footnotetext{
${ }^{2} \mathrm{At}$ the foot of the wall and on the slab, a drainage system is projected.
} 
In the calculations made with SAP2000, the vertical pressures under the slab were neglected, because when a $178^{\circ}$ angle is obtained for the thrust, as explained in previous paragraphs, the vertical component is practically zero.

For solution 2, the thrusts E1 and E4 (those located above the slab and over the foundation in the area behind the wall respectively) act at $30^{\circ}$ with the normal to the angle $\vartheta^{\prime}=60^{\circ}$ determined in Figure $4 \mathrm{~b}$, in the same way as was done for solution 1. The thrusts E2 and E5 would correspond to the law of Coulomb, with the pressures and the thrust forming an angle $\delta$ of $10^{\circ}$ (angle of friction between ground and wall) with the normal to the outer zone of the wall, while for thrust E3, as in solution 1 , the pressures would form an angle $\phi=30^{\circ}$ with the normal angle $\vartheta$.

Regardless of the solution adopted for the retaining wall, with or without a slab, in all cases the option of using the EPS as a lightening filler material in the upper area of the wall has been followed, as opposed to the alternative of using it as a compressible material for the outer zone of the wall with a vertical arrangement, following the conclusions reached by different authors (Negussey, 2008 and Horvath, 2010), in which a greater reduction of the thrust - both active and passive - was observed with this solution, as confirmed by the results obtained. It is anticipated that connectors will be executed between the preexisting concrete wall and the newly executed one by means of bars attached with epoxy resin, with the intention that both walls can work together.

Tests on two scale models (solutions 1 and 1.a, 1:40) were carried out in a second phase in order to analyze the displacements in the head of the wall elevation and at the end of the slab, since these data are considered as the most significant. Solution 1.a was chosen as it allows the model to be made with greater precision. To manufacture the models, the material chosen was wood, which has modulus of elasticity similar to that of concrete. In addition, some nails were used to ensure embedding in joints between the different pieces. Two layers of soil with the same geometry and characteristics similar to the real case were used as a filling material.

To measure displacement, a method of digital treatment of images that were taken under the same conditions was used. Three pictures were taken in each test, one before deformation and two for states of loads B and D, without modifying any optical parameter, so the position and the image increases do not change, except for the movement of the points studied, marked before the beginning of the test, at the same time that some reference points (Figure 5).The measurement of distances was made in pixels in the images, using the software of analysis and processing of digital images "ImageJ". It is a public domain program developed at the National Institutes of Health of the United States, aimed at the treatment of scientific images.

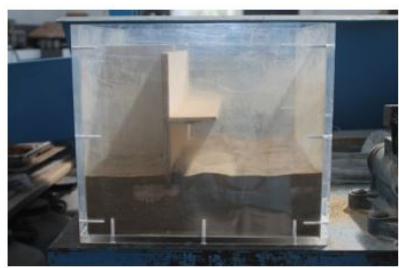

5.a.

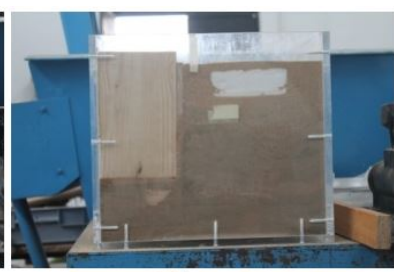

5.b.

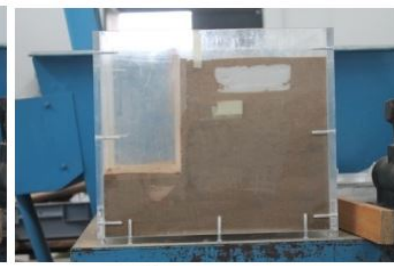

5.c.

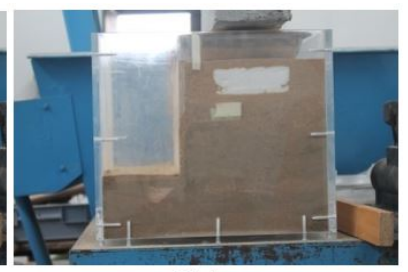

5.d.

Figure 5: test of the model with EPS blocks. 5.c and 5.d are combinations of load B and D

For the calibration of the image, distances were taken as reference on the object $(L 1, L 2, \ldots)$, which were known with precision. For this, measurements were made between well-defined marks made on the models, also using the images taken of the object without deformation. The corresponding scale of the image was obtained with these measurements, simply by dividing the reference distance between the number of corresponding pixels in the image, which gives the conversion factor $(F)$ between real distance $(\mathrm{mm})$ and virtual distance in pixels. To obtain greater precision, several calibration measurements were made, averaging the conversion factors obtained, which are usually expressed in microns per pixel. Then, to determine the displacement ( $\Delta y$, in pixels) that has occurred between two images that have been taken before and after submitting the model to a specific load, we only need to use the conversion factor:

Displacement (microns) $=\Delta y$ (pixels) $* \mathrm{~F}$ (microns/pixels)

\section{RESULTS AND DISCUSSION}

The intention to carry out a double analysis, namely a structural one with the program SAP 2000 and a geotechnical one with Plaxis 2D software, has already been anticipated. In this sense, a first analytical calculation of the slip safety will be carried out, and these results will be compared with the computer application, with an additional 
study of the behavior of the soil under the different alternatives proposed. Moreover, these results with Plaxis were contrasted with those of two scale models (solution 1 and 1.a).

To determine the slip safety conditions, the following analytical expression was used:

$C_{s d}=\frac{\left(N+E_{v}\right) \cdot \mu}{E_{h}}$

where:

$\mathrm{N}$ is the sum of weights of the wall and of the ground placed on the slab and the heel of the wall,

$E_{v}$ is the vertical component of the thrust coincident with the horizontal,

$\mu$ is the coefficient of friction between the wall and the ground at the foundation base. In our case a value of $0.58=\operatorname{tag}$ $\varphi$ is taken, and

$E_{h}$ is the horizontal component of the thrust.

If the last limit state is considered, it will result in:

$C_{s d}=\frac{\left(N+E_{v}\right) \cdot \mu+E_{p}}{E_{h}}$

where:

$E_{p}$ is the passive earth pressure

The following table (Table 2 ) summarize the results obtained for the sliding safety coefficients in combinations $B$ and $D$ in both the service limit state (S.L.S.) and the last limit (L.L.S.).

Table 2: Results of the sliding safety coefficient in the wall in solution 1 ordered from the least favorable to the optimum in solution 1.d.

\begin{tabular}{ccccccc}
\hline \multirow{2}{*}{ SOLUTION 1 } & $\begin{array}{c}\text { Solution } \\
\mathbf{1 . c}\end{array}$ & $\begin{array}{c}\text { Solution } \\
\mathbf{1 . b}\end{array}$ & $\begin{array}{c}\text { Solution 1 } \\
\text { (without } \\
\text { blocks) }\end{array}$ & $\begin{array}{c}\text { Solution } \\
\mathbf{1 . a}\end{array}$ & $\begin{array}{c}\text { Solution } \\
\mathbf{1 . d}\end{array}$ \\
\hline \multirow{2}{*}{ Csd (S.L.S.) } & Comb B & 0.85 & 1.24 & 1.49 & 1.97 & 2.8 \\
& Comb D & 0.77 & 1.18 & 1.39 & 1.81 & 2.47 \\
\multirow{2}{*}{ Csd (L.L.S.) } & Comb B & 1.5 & 1.90 & 2.18 & 2.95 & 4.3 \\
& Comb D & 1.36 & 1.79 & 2.10 & 2.71 & 3.75 \\
\hline
\end{tabular}

Table 3 contains the most relevant results obtained in terms of stresses and deformations for the wall called solution 1. As for the horizontal displacement on the wall head, it is understood that for the last state of the wall, the combination A does not have much sense, precisely because the slab is added by the favorable effect of the ground above it. However, the flexing condition of the slab itself could vary depending on the amount of compression of the ground under the slab.

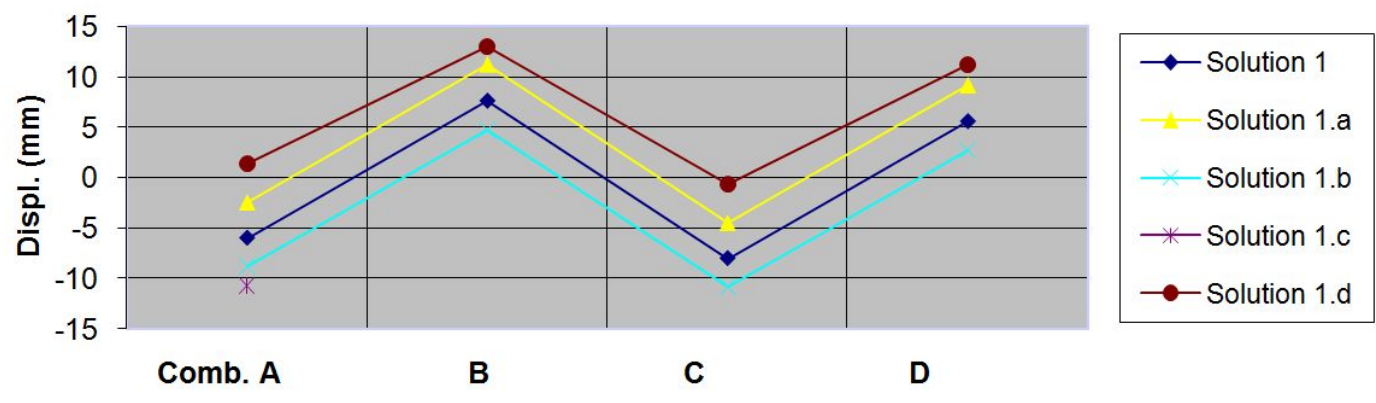

Figure 6: Comparison of horizontal displacements in the upper area of the wall obtained with the program Sap 2000. The positive sign would indicate displacement in the direction of the wall rear area (universal coordinate system). 
Observing the Figure 6 , it is seen that in the solutions a and $d$, the values of the combinations $B$ and $D$ (in the positive direction of the universal coordinate system) increase both cases, which would develop the passive thrust. As for the purely structural aspect, the most interesting solutions are " $a$ " and " $d$ ", which result in normal stresses and bending moments again smaller in the second of them.

Table 3: More unfavorable values obtained with SAP for the different options of solution 1. The coordinate system followed for the displacements is the universal one.

\begin{tabular}{|c|c|c|c|c|c|}
\hline & $\begin{array}{c}\text { Solution } 1 \\
\text { (without } \\
\text { blocks) }\end{array}$ & Solution 1.a & Solution 1.b & Solution 1.c & Solution 1.0 \\
\hline $\begin{array}{l}\text { Normal stress }{ }^{3} \\
\text { at wall start } \\
\text { (MPa) }\end{array}$ & 5.36 (C) & 3.31 (C) & $7.71(\mathrm{C})$ & 6.66 & 3.90 (B) \\
\hline $\begin{array}{l}\text { Normal stresses at the } \\
\text { head of the lower leg } \\
\text { of wall elevation (MPa) }\end{array}$ & 6.19 (B) & $5.73(B)$ & 6.19 (B) & ----- & 5.60 (B) \\
\hline $\begin{array}{l}\text { Normal stresses in the } \\
\text { slab restraint (MPa) }\end{array}$ & 4.49 (D) & 3.67 (D) & 4.47 (D) & ----- & 2.96 (D) \\
\hline $\begin{array}{l}\text { Normal stresses in } \\
\text { foundation (MPa) }\end{array}$ & 1.92 (C) & 1.22 (C) & 2.82 (C) & 2.88 & 0.99 (B) \\
\hline \multirow{2}{*}{$\begin{array}{c}\text { Horizontal } \\
\text { displacement in head } \\
\text { wall }(\mathrm{mm})\end{array}$} & $-8.01(\mathrm{C})$ & $-2.85(C)$ & $-10.88(C)$ & -11.74 & $-0.63(C)$ \\
\hline & 7.65 (B) & 4.21 (B) & 4.78 (B) & $-10.62^{4}$ & $13.03(B)$ \\
\hline \multirow{2}{*}{$\begin{array}{c}\text { Vertical displacement } \\
\text { at the free end of the } \\
\text { slab }(\mathrm{mm})\end{array}$} & 1.45 (C) & $0.25(\mathrm{C})$ & $2.62(C)$ & \multirow{2}{*}{----- } & $-0.49(\mathrm{C})$ \\
\hline & $-6.58(B)$ & $-4.49(B)$ & $-5.42(B)$ & & $-8.52(B)$ \\
\hline
\end{tabular}

Again, analyzing the combinations B and D in Figure 7, it is seen that solution $d$ (including the weight of the soil over the slab) leads to the larger values of deformation.

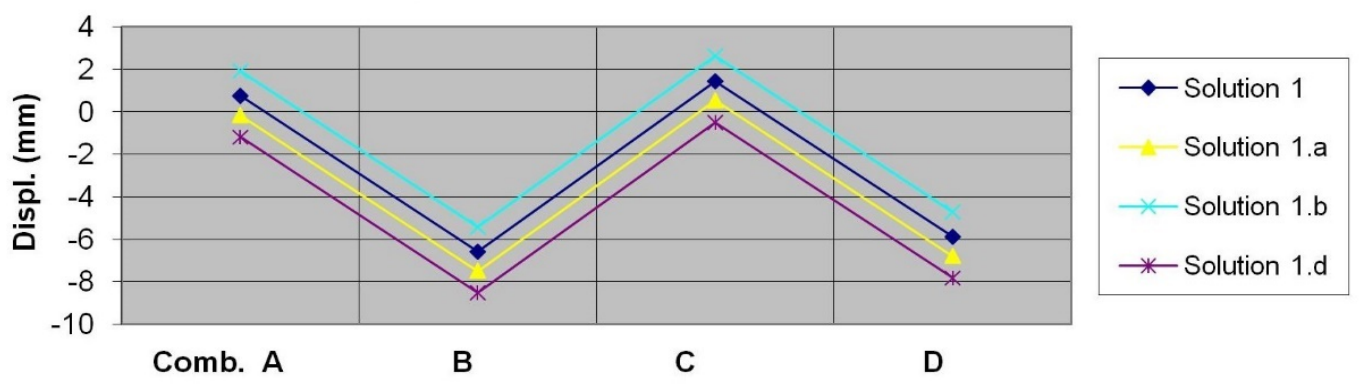

Figure 7: Comparison of vertical displacements of the slab. The positive sign would indicate ascent of the slab end (universal coordinate system). Results obtained with Sap2000.

As can be seen, the displacements are progressively moved towards the back of the wall for the three alternatives represented, which progressively reduces the thrust on the slab, without losing the beneficial effect of the weight of the land placed on it (no account was taken of the possibility of the passive pressure being mobilized using SAP2000, in which case the pressure in the upper area would increase, so the deformations would be somewhat different, without affecting the overall conclusions of this study - if it was taken into account in the calculations with Plaxis).

In view of the results obtained for this wall, it could be said that the lowest stresses are obtained for solution 1.a; it can also be seen that the stresses become more uniform for case 1.a and even more, for case 1.d; further, it can be noted that low stresses occur in the upper section of the elevation of the wall, which could lead us to consider a

\footnotetext{
${ }^{3}$ All tensions presented in this table represent values of $\sigma_{x}$ with structure criteria, in all cases being compression tensions.

${ }^{4}$ This second result has been obtained by also modeling the expanded polystyrene blocks, meaning, therefore, that the expanded polystyrene has absorbed $1.12 \mathrm{~mm}$.
} 
possible reduction of the thickness of the wall in all cases, at the cost, of course, of complicating the execution of the wall.

In the situation we have called solution 1 (with the alternatives from 1.a to 1.d), the stresses $\sigma_{x}$ (normal stresses in local axes of the elements) were studied, which allowed us to evaluate bending in the slab. In this case, we can conclude that, similarly to what has been analyzed so far, bending in the slab is progressively reduced by the three options presented. In particular, solution 1.a provides a reduction of stresses of around $13 \%$ with respect to the solution without lightening, whereas in solution 1.d the stresses are reduced by $24 \%$. We understand that these values are quite significant and can make these alternatives profitable.

Next, the results obtained for solution 2 are presented (Table 4).

Table 4: More unfavorable values obtained with SAP for the different options of solution 2. The negative values for the displacements in wall head are in the direction of the sliding (universal coordinate system). Solution $2 \mathrm{c}$ is identical to $2 \mathrm{~b}$, but the wall thickness has been reduced by $20 \mathrm{~cm}$.

\begin{tabular}{|c|c|c|c|c|}
\hline & $\begin{array}{c}\text { Solution } 2 \\
\text { (without } \\
\text { bocks) }\end{array}$ & Solution 2.a & Solution 2.b & Solution 2.c \\
\hline $\begin{array}{l}\text { Normal stress } \\
\text { at wall start } \\
\text { (MPa) }\end{array}$ & 1.12 (C) & $0.78(\mathrm{C})$ & 1.93 & $\begin{array}{c}3.87 \\
3.18(20 \mathrm{~cm})\end{array}$ \\
\hline $\begin{array}{c}\text { Normal stresses at the head } \\
\text { of the lower leg of wall } \\
\text { elevation (MPa) }\end{array}$ & 2.39 (D) & 2.10 (D) & ------- & ------- \\
\hline $\begin{array}{l}\text { Normal stresses in the slab } \\
\text { restraint (MPa) }\end{array}$ & 4.41 (D) & 3.57 (D) & -------- & -------- \\
\hline $\begin{array}{l}\text { Horizontal displacement in } \\
\text { head wall }(\mathrm{mm})\end{array}$ & $\begin{array}{l}-1.37(C) \\
0.04(B) \\
-0.31(D)\end{array}$ & $\begin{array}{l}-0.53(A) \\
0.52(B) \\
-0.87(C) \\
0.19(D)\end{array}$ & $\begin{array}{c}-2.10 \\
-2.84 \text { (without } \\
\text { EPS) }\end{array}$ & $\begin{array}{c}-3.76(20 \mathrm{~cm}) \\
-7.26 \text { (without } \\
\text { EPS) }\end{array}$ \\
\hline $\begin{array}{l}\text { Vertical displacement at the } \\
\text { free end of the slab }(\mathrm{mm})\end{array}$ & -2.51 (D) & $\begin{array}{l}-0.76(\mathrm{~A}) \\
-2.08(\mathrm{~B}) \\
-0.83(\mathrm{C}) \\
-2.15(\mathrm{D})\end{array}$ & -------- & -------- \\
\hline
\end{tabular}

This time, the results indicate that alternative 2.a is the one with the best results, being able of reducing the thickness of the wall elevation in the lower section (perhaps at the expense of complicating the reinforcement somewhat). With this option, the stresses in all areas of the wall are reduced, and the deformations are also decreased, as it can be seen that here they are practically null under all load combinations.

As for options 2.b and 2.c, it is clear that the stresses would increase - more so, of course, in the second case and the displacements would also increase. In spite of all this, these solutions should not be rejected, because in any case, the displacements are kept within admissible values and these solutions can achieve some economic savings, as it is possible, as already mentioned in previous paragraphs, to place blocks of EPS in a staggered form within the area occupied by the sliding surface at a depth greater than the $2 \mathrm{~m}$, as studied in cases 2.b and 2.c.

Something similar could be said of solution 2.a: the effect of regularizing the stresses in the wall elevation, which can be noticed in its lower area, is again appreciated. If it were possible to obtain more uniform values of wall bending, this would result in a better use of the reinforcement used, at least for the steel bar required by traction.

Finally, the proposal to perform the filling with EPS blocks in a staggered way could be of interest for saving the maximal amount of material until a greater depth is reached, so that the thrust height is reduced to 4 or $4.5 \mathrm{~m}$, which it would be necessary to place blocks of EPS that occupy a depth of more than $3 \mathrm{~m}$. However, the case in question is somewhat different, as there is already a preexisting wall, so a block depth of $3 \mathrm{~m}$ could be sufficient, in addition to reducing the thickness of the projected wall somewhat.

In the graphs shown (Figures 8 and 9), it is possible to see, in addition to the reductions in the total and horizontal displacements, two aspects of interest: firstly, the slight compression effect that occurs in the blocks of EPS in the two solutions analyzed here (an effect that may have been altered in this first-order calculation by the soil, by which it seems "hung" of the wall), and secondly how the gradient of horizontal displacements in the upper section of the wall elevation decreases slightly, so that for solutions 1.a. and 1.d., this gradient of displacements is significantly lower. As 
far as the compression of the polystyrene is concerned, this result is in agreement with the model that was made with the SAP software including blocks, and leads to a reduction of approximately $1 \mathrm{~mm}$ in the horizontal deformations between the initial model and the proposed solutions (1.a and 1.d).

\section{Thrust comparative}

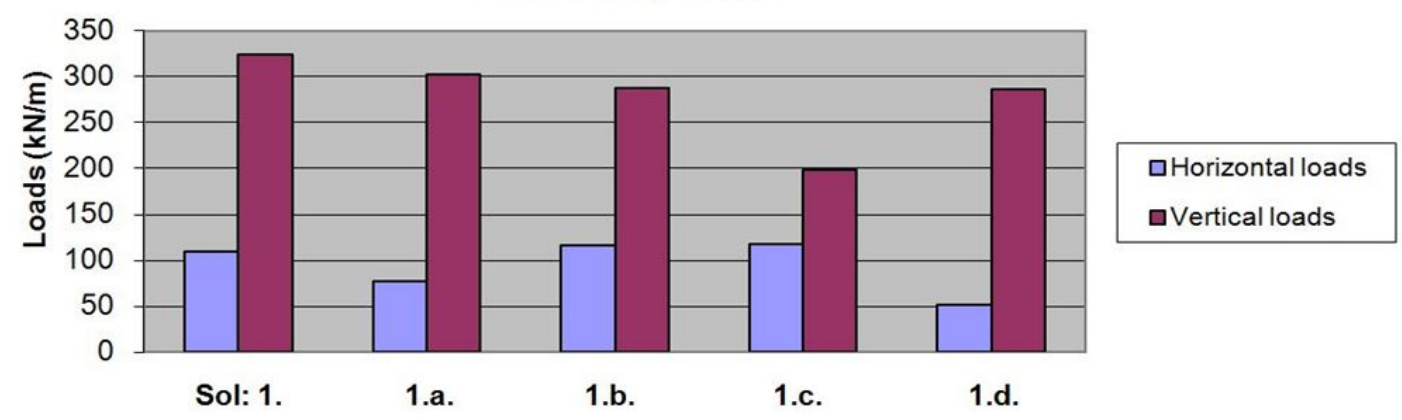

Ev/Eh

(including wall weight)

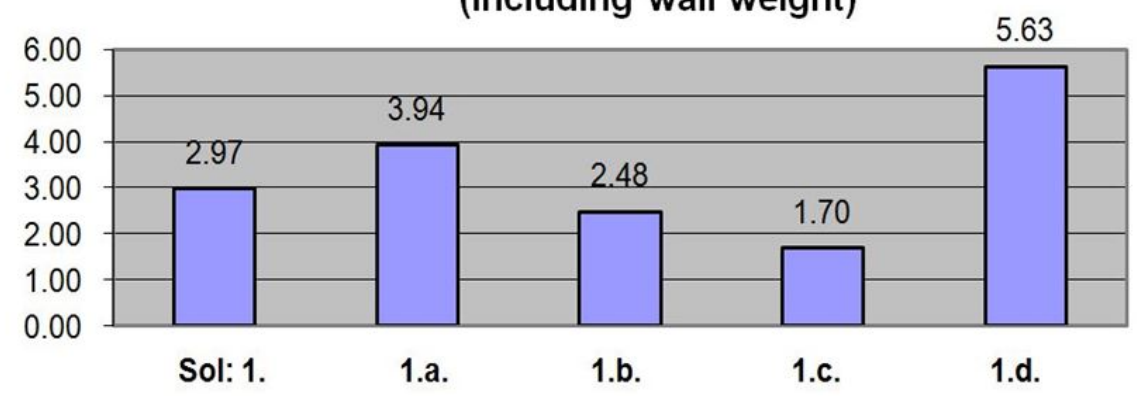

Figure 8: Comparison of thrust and relationship between horizontal and vertical thrust. Solution 1 wall.

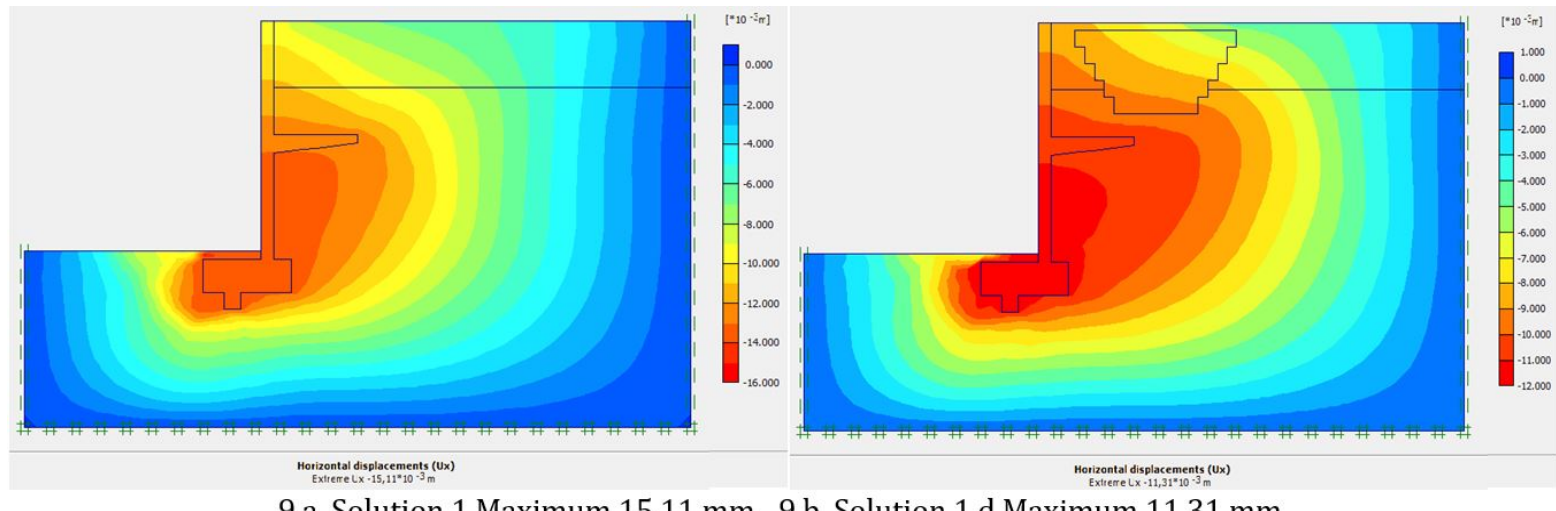

9.a. Solution 1,Maximum $15.11 \mathrm{~mm}$. 9.b. Solution 1.d Maximum $11.31 \mathrm{~mm}$.

Figure 9: Horizontal displacement. E 1:100.

If the results for the displacement on the head wall (obtained with the calculations in Plaxis as the difference between the horizontal displacements between the foot and head of the wall elevation) are compared, the results obtained with Plaxis are somewhat lower than those obtained with SAP2000 (5.29, 4.25, and 3.12 versus 7.65, 4.22, and 2.35 for combination B); however, while with SAP the results of both the displacement on the head wall and at the end of the slab increase with solution 1.a and do so even more with solution 1.d., here the effect is just the opposite. This leads us to think of the alteration experienced by the sliding surface with the inclusion of the EPS blocks. 


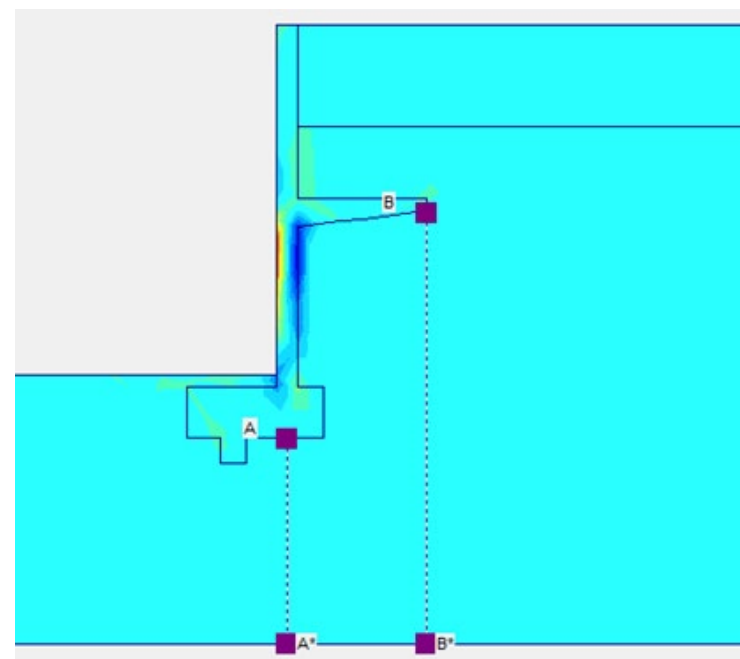

Figure 10: Location of sections $A A^{\prime}$ and $B B^{\prime}$.

Comparing the results of the deformations in Table 5, it is seen, as the most relevant aspect, that the displacement that is most reduced with the proposed alternatives is in all cases the horizontal one, so we can conclude that with regard to sliding, the inclusion of this lightening filler material offers important advantages. If we notice the pressure results in sections $A A^{\prime}$ and $B B^{\prime}$ (see Figure 10), note that while for section $A A^{\prime}$ both effective and total pressures experience slight fluctuations, in the case of section BB' located just below the slab, and therefore below the filling area, there is a clear reduction of the pressures. In addition, it is convenient to clarify that with regard to the possible settlements caused by the use of the EPS blocks, the maximum settlement for solution $1 . d$ is reduced by a little more than $1.5 \mathrm{~mm}^{5}$.

Table 5: Comparative results obtained in Plaxis for the Solution 1 wall.

(Section $A A^{\prime}$ and $B B^{\prime}$ are defined in Figure 10.)

\begin{tabular}{|c|c|c|c|c|c|c|c|c|}
\hline & & & \multicolumn{2}{|c|}{$\begin{array}{c}\text { Solution } 1 \\
\text { (without EPS) }\end{array}$} & \multicolumn{2}{|c|}{ Solution 1.a } & \multicolumn{2}{|c|}{ Solution 1.d } \\
\hline & & & Comb B & Comb D & Comb B & Comb D & Comb B & Comb D \\
\hline \multicolumn{3}{|c|}{$\begin{array}{l}\text { Total displacement } \\
\text { (maximum-mm) }\end{array}$} & -16.16 & -24.53 & -13.71 & -17.06 & -13.37 & -16.49 \\
\hline \multicolumn{3}{|c|}{$\begin{array}{l}\text { Horizontal displa- } \\
\text { cement (maximum-mm) }\end{array}$} & -16.00 & -23.76 & -13.64 & -16.20 & -11.79 & -14.07 \\
\hline \multicolumn{3}{|c|}{$\begin{array}{c}\text { Vertical displa- } \\
\text { cement (maximum-mm) }\end{array}$} & -13.54 & -20.20 & -13.00 & -16.03 & -12.60 & -15.76 \\
\hline \multirow{2}{*}{\multicolumn{2}{|c|}{$\begin{array}{l}\text { Displacement under } \\
\text { foundation }(\mathrm{mm})\end{array}$}} & Ux & -14.10 & -19.39 & -12.13 & -13.81 & -11.57 & -12.95 \\
\hline & & Uy & -1.90 & -5.30 & -1.18 & -2.27 & -0.83 & -1.77 \\
\hline \multirow{2}{*}{\multicolumn{2}{|c|}{$\begin{array}{l}\text { Displacement on } \\
\text { head wall }(\mathrm{mm})\end{array}$}} & Ux & -8.95 & -18.01 & -8.13 & -11.72 & -8.02 & -11.67 \\
\hline & & Uy & -2.08 & -4.93 & -1.37 & -2.08 & -0.94 & -1.56 \\
\hline \multirow{2}{*}{\multicolumn{2}{|c|}{$\begin{array}{l}\text { Displacement at the } \\
\text { end of slab }(\mathrm{mm})\end{array}$}} & Ux & -12.86 & -20.61 & -11.27 & -13.06 & -10.94 & -13.05 \\
\hline & & Uy & -5.45 & -7.87 & -3.85 & -4.47 & -2.76 & -3.27 \\
\hline \multicolumn{3}{|c|}{$\begin{array}{l}\text { Effective pressure } \sigma_{y}^{\prime} \\
\qquad\left(\mathrm{kN} / \mathrm{m}^{2}\right)\end{array}$} & $-220 /-287$ & $-228 /-298$ & $\begin{array}{l}-218 /- \\
284\end{array}$ & $-221 /-282$ & $-219 /-280$ & $-221 /-287$ \\
\hline$A A^{\prime}$ & \multicolumn{2}{|c|}{$\begin{array}{c}\text { Total pressure } \\
\sigma_{y}\left(\mathrm{kN} / \mathrm{m}^{2}\right)\end{array}$} & $-160 / 250$ & $-185 /-268$ & $\begin{array}{l}-152 /- \\
237\end{array}$ & $-165 /-247$ & $\begin{array}{l}-162 /-226 \\
-145 /-226\end{array}$ & $\begin{array}{l}-172 /-233 \\
-152 /-233\end{array}$ \\
\hline \multirow{2}{*}{$\begin{array}{l}\text { Section } \\
\text { BB' }^{\prime}\end{array}$} & \multicolumn{2}{|c|}{$\begin{array}{l}\text { Effective pressur } \\
\qquad \sigma_{y}^{\prime}\left(\mathrm{kN} / \mathrm{m}^{2}\right)\end{array}$} & -220 & -220 & -194 & -194 & -176 & -176 \\
\hline & \multicolumn{2}{|c|}{$\begin{array}{c}\text { Total pressure } \\
\sigma_{\mathrm{y}}\left(\mathrm{kN} / \mathrm{m}^{2}\right)\end{array}$} & -201 & -203 & -185 & -188 & -174 & -178 \\
\hline
\end{tabular}

${ }^{5}$ The shortening observed in EPS blocks has reached a maximum value of $1.4 \mathrm{~mm}$ for 1.a solution and $1.7 \mathrm{~mm}$ for $1 . \mathrm{d}$, which are considered admissible values for ground/EPS/structure system. 


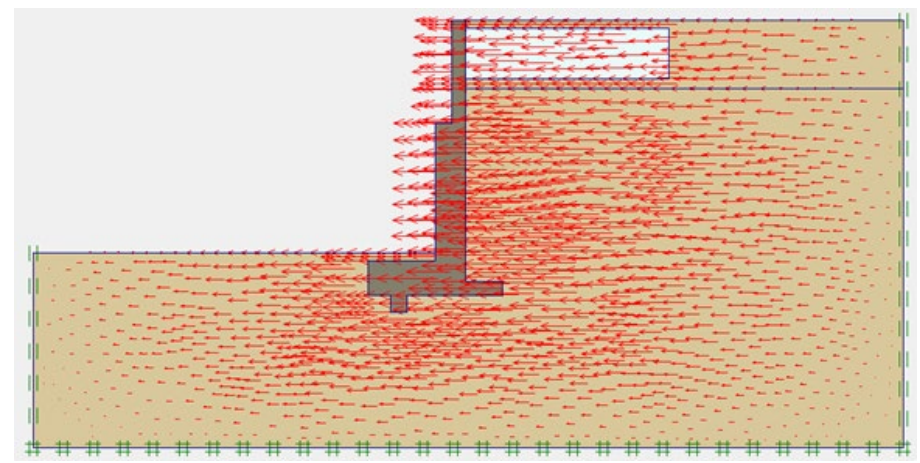

Figure 11: Solution 2.b - Combination B. Horizontal displacements. Horizontal maximum $13.54 \mathrm{~mm}$ (absolute maximum $14.33 \mathrm{~mm}$ ).

With respect to the wall in solution 2, it was possible to observe in the different deformation graphs, how gradually, and fundamentally in the last one of them (solution 2.b), the turning movement was disappearing, until in the solution 2, the wall moved almost horizontally without any turning (Figure 11), except in the upper section with less rigidity. This is seen more clearly in Figure 11, in which the displacements are represented by vectors.

Reviewing the values in Table 6 confirms what has been said in the previous paragraphs regarding the significant improvement in slip stability obtained with the two new alternatives, and also is confirming for the combination $\mathrm{B}$, as the relative horizontal displacements between the support of the wall and its head are reduced to less than $2 \mathrm{~mm}$ in the case of the third solution for this sort of wall and also, although to a lesser extent, in the case of the second (2.a). However, this phenomenon already appears in the case of the three alternatives for the combination $D$ in which the surface load is included, which appears to partially compensate for the effect of lightening by EPS.

Table 6: Comparative results obtained with Plaxis for the wall solution 2. The pressures indicated in section AA' represent the maximum value and the value measured at $25 \mathrm{~cm}$ under the wall support in a section under the area behind the wall.

\begin{tabular}{|c|c|c|c|c|c|c|c|c|}
\hline & & & \multicolumn{2}{|c|}{$\begin{array}{c}\text { Solution } 2 \\
\text { (without EPS) }\end{array}$} & \multicolumn{2}{|c|}{ Solution 2.a } & \multicolumn{2}{|c|}{ Solution 2.b } \\
\hline & & & Comb B & Comb D & Comb B & Comb D & Comb B & Comb D \\
\hline \multicolumn{3}{|c|}{$\begin{array}{l}\text { Total displacement } \\
\text { (maximum-mm) }\end{array}$} & -15.40 & -19.38 & -13.97 & -18.12 & -14.33 & -18.48 \\
\hline \multicolumn{3}{|c|}{$\begin{array}{l}\text { Horizontal displa- } \\
\text { cement (maximum-mm) }\end{array}$} & -15.40 & -19.29 & -13.63 & -16.37 & -13.54 & -16.35 \\
\hline \multicolumn{3}{|c|}{$\begin{array}{c}\text { Vertical displa- } \\
\text { cement (maximum-mm) }\end{array}$} & -13.10 & -17.24 & -13.77 & -17.09 & -14.25 & -17.42 \\
\hline \multirow{2}{*}{\multicolumn{2}{|c|}{$\begin{array}{l}\text { Displacement under } \\
\text { foundation }(\mathrm{mm})\end{array}$}} & Ux & -15.19 & -18.04 & -13.47 & -15.56 & -13.34 & 15.45 \\
\hline & & Uy & -1.33 & -3.23 & -0.91 & -2.07 & -0.43 & -1.27 \\
\hline \multirow{2}{*}{\multicolumn{2}{|c|}{$\begin{array}{l}\text { Displacement on } \\
\text { head wall }(\mathrm{mm})\end{array}$}} & Ux & -11.31 & -18.38 & -10.02 & -14.78 & -11.24 & -15.38 \\
\hline & & Uy & -2.28 & -3.16 & -1.75 & -2.27 & -0.93 & -1.26 \\
\hline \multirow{2}{*}{\multicolumn{2}{|c|}{$\begin{array}{l}\text { Displacement at the } \\
\text { end of slab }(\mathrm{mm})\end{array}$}} & Ux & -12.91 & -18.03 & -11.51 & -15.00 & \multirow{2}{*}{---} & \multirow{2}{*}{---- } \\
\hline & & Uy & -4.78 & -5.05 & -3.60 & -3.87 & & \\
\hline \multirow{2}{*}{$\begin{array}{l}\text { Section } \\
\mathrm{AA}^{\prime}\end{array}$} & \multicolumn{2}{|c|}{$\begin{array}{l}\text { Effective pressure } \sigma_{y}^{\prime} \\
\qquad\left(\mathrm{kN} / \mathrm{m}^{2}\right)\end{array}$} & $-202 /-286$ & $-201 /-284$ & $-188 /-271$ & $-185 /-274$ & $-202 /-260$ & $-202 /-262$ \\
\hline & \multicolumn{2}{|c|}{$\begin{array}{c}\text { Total pressure } \\
\sigma_{\mathrm{y}}\left(\mathrm{kN} / \mathrm{m}^{2}\right)\end{array}$} & $-170 / 232$ & $-178 /-244$ & $-156 /-230$ & $-162 /-238$ & $-150 /-222$ & $\begin{array}{l}-163 /-222 \\
-153 /-222\end{array}$ \\
\hline \multicolumn{3}{|c|}{$\begin{array}{l}\text { Effective pressure } \\
\qquad \sigma_{y}^{\prime}\left(k N / m^{2}\right)\end{array}$} & -226 & -226 & -200 & -200 & -200 & -200 \\
\hline $\mathrm{BB}^{\prime}$ & \multicolumn{2}{|c|}{$\begin{array}{c}\text { Total pressure } \\
\sigma_{\mathrm{y}}\left(\mathrm{kN} / \mathrm{m}^{2}\right)\end{array}$} & -207 & -207 & -193 & -194 & -189 & -191 \\
\hline
\end{tabular}

Comparing the results of both effective and total pressures in Tables 5 and 6 , the different evolutions followed by sections $A A^{\prime}$ and $B B^{\prime}$ can be seen, of which the $\mathrm{BB}^{\prime}$ section is the most notable, being affected by the different positions and thicknesses of the lightening blocks. 
For the scale models, the results obtained are presented in Figure 12, considering that 14 tests were carried out on each model, eliminating the two lowest and highest. Table 7 shows the average of these results corrected by the scale factor, comparing them with those achieved with Plaxis.
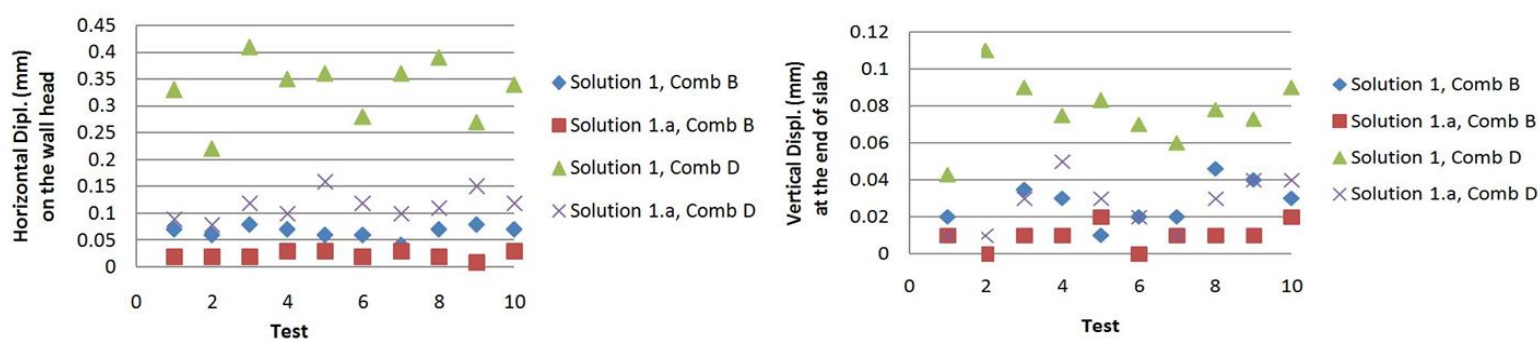

Figure 12: results obtained in the tests of the scale models

Table 7: Comparative results obtained by the scale models and Plaxis for the solution 1 and 1.a.

(the sub-index sc refers to tests in the scale models)

\begin{tabular}{|c|c|c|c|c|c|}
\hline & & \multicolumn{2}{|c|}{$\begin{array}{c}\text { Solution } 1 \\
\text { (without blocks) }\end{array}$} & \multicolumn{2}{|c|}{ Solution 1.a } \\
\hline & & Comb B & Comb D & Comb B & Comb D \\
\hline \multirow{2}{*}{$\begin{array}{c}\text { Horizontal } \\
\text { displacement in head } \\
\text { wall }(\mathrm{mm})\end{array}$} & Ux & -8.95 & -18.01 & -8.13 & -11.72 \\
\hline & Ux,sc & -2.64 & -13.24 & -0.92 & -4.60 \\
\hline \multirow{2}{*}{$\begin{array}{l}\text { Vertical displacement } \\
\text { at the free end of the } \\
\qquad \operatorname{slab}(\mathrm{mm})\end{array}$} & Uy & -5.45 & -7.87 & -3.85 & -4.47 \\
\hline & Uy,sc & -1.03 & -3.16 & -0.41 & -1.08 \\
\hline
\end{tabular}

The tests carried out on the two models (solutions 1 and 1.a) have confirmed a significant decrease in displacements, both at the head of the wall and at the end of the slab. The results achieved with EPS blocks are almost $35 \%$ of those obtained without EPS blocks for the combination D, and are more significant than ones using numerical methods, despite the fact that the small consolidation that could happen in soil could not be taken into account in the tests.

Regardless of the advantages observed in this research, it is important to keep in mind the aspect of durability when intending to use EPS. Although, as a general rule, EPS is quite stable in terms of degradation, certain precautions must be taken in its use, as indicated by Lin et al. (2010) and Vilaverde (2009): contact must be avoided with all petroleum products, certain solvents, and aggressive waters, in which case the EPS must be protected with geomembrane barriers or another solution. A good preparation of the site is important to placing the EPS blocks properly, because each layer of blocks should be placed as level as possible to avoid stress concentrations and rocking of the EPS blocks (Stark et al, 2004). Water alone is not an aggressive agent; however, water uptake by EPS may be a route of further degradation by other agents. In addition, the buoyancy problems of the EPS should be considered in the event of a high groundwater level, for which an adequate drainage system would be necessary.

\section{CONCLUSIONS}

An alternative to a real problem was approached in this paper, for which two different solutions were already given in the proposals for the 2011 project depending on the particular conditions. In view of the results and the corresponding subsequent analysis, the following fundamental conclusions can be drawn:

Of the different alternatives proposed, it is clear, as expected, that the most favorable are those that substitute part of the natural land for pieces of expanded polystyrene in the area occupied by the sliding surface above the slab, but maintaining a filling of granular type above this, so the slab does not lose its favorable effect.

The difference between using blocks of more or less constant width and, on the contrary, placing the blocks in a step-wise manner does not present a clear conclusion. Although the latter presents an optimum performance from a technical point of view, it complicates the execution somewhat, so it may not be the most suitable alternative, which, in each case, must be analyzed. However, the differences are minimal in the case that has been studied here. 
As a general conclusion, it should be added that regardless of the solution adopted, in all models, by including the EPS blocks, the sliding surface is altered depending on the volume occupied by the lightweight material supplied, which agrees with the findings of Tsukamoto et al. (2002).

The low stresses in the upper section of the wall elevation allow the reduction of the wall thickness in this area and, as a consequence, an economic saving. Additionally, it can be concluded that the bending of the slab is progressively reduced in the options that have been presented and that the sliding safety coefficient increases markedly when the EPS blocks are used. The displacements are reduced in the solutions proposed with respect to the initial solution.

As a complement to the numerical analysis, a set of tests were made with scale models, which have found good agreement with the finite element analysis and also verify that the proposed solutions have important advantages: reduction of pressures, stresses and displacements

Finally, recall the comments and recommendations presented in the previous section about durability and construction procedure.

\section{REFERENCES}

Calavera, J. (2001). Muros de Contención y Muros de Sótano, Intemac. Madrid.

Coulomb, C.A. (1773). Essai sur Quelques Problemes de Statique Relatis a L'Architecture, Academie Royale des Sciences. París.

Davila, J.M., Fortes, J.C., Crespo, L., Rodriguez, C.A. (2015). Comparative analysis of slabs foundation: lightweight by expanded polystyrene blocks opposite solid slab. Informes de la Construcción. 67 [538], e080. http://dx.doi.org/10.3989/ic.13.157.

Ertugrul, O. L., Trandafir, A C., (2013). Lateral earth pressures on flexible cantilever retaining walls with deformable geofoam inclusions. Engineering Geology. 158 [24]: 23-33. http://dx.doi.org/10.1016/j.enggeo.2013.03.001.

Ertugrul, O.L., Trandafir, A.C., (2011). Reduction of Lateral Earth Forces Acting on Rigid Nonyielding Retaining Walls by EPS Geofoam Inclusions. ASCE. 23. http://dx.doi.org/10.1061/(ASCE)MT.1943-5533.0000348.

Geotechnical study of the work for the new lookout in the "Homenaje Tower" of the Utrera's Castle (2011). CODEXSA.

Horvath, J. (1997). The compressible inclusion function of EPS geofoam. Geotextiles and Geomembranes. 15 [1-3]: 77-120. https://doi.org/10.1016/S0266-1144(97)00008-3.

Horvath, J.S. (2010). Lateral Pressure Reduction on Earth-Retaining Structures Using Geofoams: Correcting some misunderstandings. ASCE, ER2010: Earth Retention Conference: 862-869. http://dx.doi.org/10.1061/41128(384)86.

Ikizler, S.B., Aytekina, M., Nasb, E., (2007). Laboratory study of expanded polystyrene (EPS) geofoam used with expansive soils. Geotextiles and Geomembranes. 26: 1819-195. http://dx.doi.org/10.1016/j.geotexmem.2007.05.005.

Jaramillo, A. (2011). Comprobación y Cálculo de Muros de Contención en la Muralla del Castillo de Utrera (Sevilla).

Jiménez, J.A., de Justo, J.L., Serrano, A.A., (1981). Geotécnica y Cimientos II, Rueda. Madrid.

Lima, M. (2010). Basic project and execution of the conservation of the wall of Utrera's Castle (Sevilla).

Lin, L.K., Chen, L.H., Chen, R.H.L., (2010). Evaluation of Geofoam as a Geotechnical Construction Material. Journal of Materials In Civil Engineering. 22: 160-170. http://dx.doi.org/10.1061/(ASCE)0899-1561(2010)22:2(160).

Miao, L., Wang, F., Han, J., Lv, W., Li, J., (2013). Properties and Applications of Cement-Treated Sand-Expanded Polystyrene Bead Lightweight Fill. Journal of Materials in Civil Engineering. 25: 86-93. http://dx.doi.org/10.1061/(ASCE)MT.19435533.0000556 .

Negussey, D. (2008). Design Parameters for EPS Geofoam. Soils and Foundations. 48 [1]: 861. http://doi.org/10.3208/sandf.48.861.

Plaxis 2D, Scientific Manual, (2016).

Stark, T.D., Horvath, J.S., Leshchinsky, D., (2004). Geofoam application in Design and Construction of Highway Embankments. Transportation Research Board, 65: 6.53-6.56.

Tsukamoto, Y., Ishihara, K., Kon, H., Masuo, T., (2002). Use of comprenssible expanded polystyrene blocks and geogrids for retaining wall structures. Soil and Foundations. 42 [4]: 29-41. http://doi.org/10.3208/sandf.42.4_29. 
Valdbjørn, T. (2010). Integrated Strip Foundation Systems for Small Residential Buildings. The Open Construction and Building Technology Journal 4: 39-53. http://doi.org/10.2174/1874836801004010039.

Vilaverde, J. (2009). Estudo do Envelhecimento Físico de um Polímero Estrutural. Univ of Trasos-montes and Alto Douro (Portugal).

Zarnani, A., Bathurst, R.J., (2009). Numerical parametric study of expanded polystyrene (EPS) geofoam seismic buffers. Canadian Geotechnical Journal. 46 [3]: 318-338. http://dx.doi.org/10.1139/T08-128. 